\title{
Breast cancer risk and lifetime occupational history: employment in professional and managerial occupations
}

Sandra A Petralia, John E Vena, Jo L Freudenheim, James R Marshall, Arthur Michalek, John Brasure, Mya Swanson, Saxon Graham
Department of Social and Preventive Medicine, State University of New York, Buffalo, USA S A Petralia

J E Vena

J L Freudenheim

J Brasure

M Swanson

S Graham

Arizona Cancer Center, Tucson, Arizona, USA J R Marshall

Roswell Park Cancer Institute, Buffalo, New York,USA

A Michalek

Correspondence to: Dr Sandra A Petralia, Occupational Epidemiology Branch, National Cancer Institute, Executive Plaza North, Rm 418, 6130 Executive Boulevard, Bethesda, Maryland 20892, USA. Tel: 0013014969093 Fax: 0013014021819.

Accepted 17 July 1997

\begin{abstract}
Objective-In this case-control study, occupational histories were used to assess the relation between risk of breast cancer and employment in professional and managerial occupations while adjusting for reproductive and other risk factors.

Methods-Incident, primary, female cases of breast cancer diagnosed between 1986 and 1991, and randomly selected controls were interviewed to obtain detailed medical, reproductive, and occupational histories. Mantel-Haenszel crude odds ratios (OR) and $95 \%$ confidence intervals $(95 \%$ CIs) were used to estimate risk of breast cancer related to the job of longest duration. Unconditional logistic regression was used to estimate crude and adjusted ORs and $95 \%$ CIs associated with having ever been employed and duration of employment in a professional or managerial occupation.

Results-A non-significant threefold increase in risk was found among premenopausal women whose major job was in the occupational category of precision production, craft, and repair (95\% CI 0.90 to 20.35). No increase in risk was found for premenopausal women whose major job was a managerial or professional occupation. However, an inverse relation between risk of premenopausal breast cancer and having ever held a professional or managerial job was observed (OR $0.53,95 \%$ CI 0.34 to 0.82 ). This relation was strongest for women who worked one to 10 years (OR 0.47, 95\% CI 0.29 to 0.77). Postmenopausal breast cancer was not related to professional and managerial employment. Conclusions-In this population, employment in professional and managerial occupations is not associated with postmenopausal risk of breast cancer, but seems to be related to a reduction in risk of premenopausal breast cancer. Methodological limitations of this study including response rates are discussed. (Occup Environ Med 1998;55:43-48)
\end{abstract}

Keywords: breast cancer; occupation; epidemiology; case-control

Breast cancer is one of the two most common cancers among women in industrialised countries $^{1}$ and the incidence of breast cancer has been rising in many countries worldwide over the past decade. ${ }^{23}$
Little is known about the occupational risk factors for breast cancer. However, there have been studies suggesting that higher socioeconomic status is related to higher risks of breast cancer, ${ }^{2-7}$ an association which may relate to occupation. Goldberg and Labrèche ${ }^{8}$ recently published a comprehensive review of the occupational epidemiology of breast cancer. One of the most consistent results of previous studies was the observation of an increased risk associated with professional and managerial occupations. ${ }^{9-18}$ Increased risk of breast cancer has been found for specific occupational titles in this category, particularly nurse ${ }^{1013-15}$ and teacher. $^{91012131718}$ Other studies found an increased risk among women exposed to solder flux. ${ }^{19}{ }^{20}$ Freon, isopropyl alcohol, ${ }^{19}$ methylene chloride ${ }^{21}$ styrene, acid mists, and certain metals ${ }^{20}$ have each been associated with risk of breast cancer in individual studies, findings which need to be replicated. There is some evidence that female cosmetologists may have an increased risk of breast cancer compared with other women. ${ }^{11}{ }^{1822-25}$ Studies examining risk of breast cancer associated with occupations involving potential exposure to electromagnetic fields have produced inconsistent findings. ${ }^{1016172627}$ The only established occupational risk factor for breast cancer is exposure to ionising radiation. Increased risk of breast cancer was found among radium dial painters ${ }^{28-30}$ and among women occupationally exposed to radiation through diagnostic $x$ ray films. ${ }^{31}$ However, in two recent studies no increase of risk was found among radiological technologists. ${ }^{32} 33$

Data on known reproductive risk factors often related to employment patterns such as age at first pregnancy or birth and parity were unavailable in most previous studies. ${ }^{9-31}$ Also, many occupational studies measured risk in relation to current ${ }^{11}$ occupation or usual occupation as listed on death certificates. . 1012 13 15-17 202223 These measures omit occupational exposures related to other jobs held throughout participants' lives. In our study, we use lifetime occupational histories to examine risk of breast cancer associated with occupation of longest duration. Also, because of the evidence linking risk of breast cancer to professional and managerial employment, we used these histories to assess risk of breast cancer among women who held at least one professional or managerial job, with analyses adjusted for other known risk factors for breast cancer. 


\section{Methods}

This study is part of a case-control study conducted in western New York State which was designed to identify risk factors for premenopausal and postmenopausal breast cancer. ${ }^{34} 35$ Women who were at least 40 years of age were eligible for inclusion in the study. Women were considered postmenopausal if they had stopped menstruation and were 50 years of age or older, or if they were under the age of 50, if they had experienced natural menopause or menopause because of medical intervention such that neither ovary was functioning. Incident, primary, histologically confirmed cases of breast cancer were identified from all major hospitals in Erie and Niagara Counties in New York State between 1986 and 1991. Sixty six per cent (301) of premenopausal and $53 \%$ (439) of postmenopausal eligible cases participated in the study.

Controls were residents of the same two counties as the cases. Those under 65 were randomly selected from the Department of Motor Vehicles lists and those 65 and older were randomly selected from healthcare finance administration lists. Controls were frequency matched to cases on age and county of residence. Sixty two per cent (316) of the premenopausal and $44 \%$ of the postmenopausal women identified participated as controls. All participants signed an informed consent granting us an interview and cases also gave us permission to review their hospital records. Personal interviews were conducted to obtain data on dietary habits, demographic characteristics, reproductive and menstrual history, medical history, lifestyle factors, and family history of breast cancer.

To obtain complete and standardised lifetime occupational histories, the interviewers received special training. Participants were asked to recall all jobs held for at least one year or longer beginning with the job they held two years before the interview and working backwards. For each job held, participants provided job title, duties, and activities associated with each title, the calendar years during which the job was held, and whether it was full time or part time. Interviewers also obtained each employer's name, address, and a description of what the company manufactured or did. Each occupational title and industry was coded by a trained research clerk according to the United States 1980 Bureau of Census codes. ${ }^{36}$ Employment status two years before the interview

Table 1 Employment status two years before the interview among premenopausal and postmenopausal participants

\begin{tabular}{|c|c|c|c|c|c|c|c|c|}
\hline \multirow[b]{3}{*}{ Employment } & \multicolumn{4}{|c|}{ Premenopausal } & \multicolumn{4}{|c|}{ Postmenopausal } \\
\hline & \multicolumn{2}{|c|}{ Cases } & \multicolumn{2}{|c|}{ Controls } & \multicolumn{2}{|c|}{ Cases } & \multicolumn{2}{|c|}{ Controls } \\
\hline & $n$ & $(\%)$ & $n$ & $(\%)^{*}$ & $n$ & $(\%)^{*}$ & $n$ & $(\%)$ \\
\hline Never employed & 11 & (3.7) & 8 & $(2.5)$ & 18 & $(4.1)$ & 25 & $(5.1)$ \\
\hline Currently employed & 231 & (76.7) & 251 & (79.4) & 184 & $(41.9)$ & 204 & $(41.3)$ \\
\hline Retired & 43 & (14.3) & 42 & (13.3) & 221 & $(50.3)$ & 240 & $(48.6)$ \\
\hline Worked previously & 16 & $(5.3)$ & 14 & $(4.4)$ & 16 & $(3.6)$ & 18 & $(3.6)$ \\
\hline Missing & 0 & $(0.0)$ & 1 & $(0.3)$ & 0 & $(0.0)$ & 7 & (1.4) \\
\hline Total & 301 & $(100.0)$ & 316 & (99.9) & 439 & $(99.9)$ & 494 & $(100.0)$ \\
\hline
\end{tabular}

^Percentages do not add to 100.0 due to rounding. and total number of jobs held were compared between cases and controls.

The entire occupational history was used to determine each woman's job of longest duration (main job). Women whose major job was not in the occupation or occupational category under investigation served as the control group in each analysis. Mantel-Haenszel ${ }^{37}$ crude odds $^{-}$ ratios (ORs) and 95\% confidence intervals (95\% CIs) were used to estimate risk related to employment in each occupational category.

To further assess risk of breast cancer relative to employment in the managerial and professional specialty category (census codes 3-199), women were classified as ever exposed if their occupational history included at least one professional or managerial job. Categories for duration of employment in these occupations were determined according to the distribution of total years worked in all jobs in such occupations among premenopausal controls. These same categories were used in the analysis among postmenopausal women for comparability between premenopausal and postmenopausal risk of breast cancer. Women who never were employed in a managerial or professional specialty occupation served as the control group. Women who were missing an occupational title and did not have a job in the managerial or professional specialty category listed in their occupational history were considered as missing and excluded from all analyses. Similarly, women without data on the number of years worked in a managerial or professional job, were considered to be missing total years worked in these occupations and were excluded from the duration of employment analyses. Crude and adjusted ORs were estimated with SPSS logistic regression. ${ }^{38} 39$ The $95 \%$ CIs were calculated using $\beta$ coefficients (SEMs). ${ }^{38}$ Factors selected for addition to statistical models were based on their status as established risk factors for breast cancer and on results of analyses of non-occupational risk factors for breast cancer using these data. ${ }^{34}$

\section{Results}

Table 1 shows participants' employment two years before the interview. Among premenopausal women, only $3.7 \%$ of cases and $2.5 \%$ of controls were never employed and most cases $(76.7 \%)$ and controls $(79.4 \%)$ were employed two years before the interview. Among postmenopausal women, only $4.1 \%$ of cases and $5.1 \%$ of controls were never employed and $50.4 \%$ of cases and $48.5 \%$ of controls were retired two years before the interview. A small percentage of both premenopausal and postmenopausal cases and controls were employed in the past and had ended employment without retiring. More than $25 \%$ of cases and $30 \%$ of controls among premenopausal and postmenopausal women held five or more jobs throughout their lifetime.

Table 2 shows the risk of premenopausal and postmenopausal breast cancer associated with the category of the major job. No increase in risk was found among premenopausal women whose main job was a managerial or professional specialty occupation (OR $0.87,95 \%$ CI 
Table 2 Occupational category of job of longest duration and risk of premenopausal and postmenopausal breast cancer

\begin{tabular}{|c|c|c|c|c|c|c|}
\hline \multirow[b]{2}{*}{ Occupation } & \multicolumn{3}{|c|}{ Premenopausal } & \multicolumn{3}{|c|}{ Postmenopausal } \\
\hline & $\begin{array}{l}\text { Cases } \\
n\end{array}$ & $\begin{array}{l}\text { Controls } \\
n\end{array}$ & $\begin{array}{l}\text { Crude } \\
\text { OR }(95 \% C I)^{*}\end{array}$ & $\begin{array}{l}\text { Cases } \\
n\end{array}$ & $\begin{array}{l}\text { Controls } \\
n\end{array}$ & $\begin{array}{l}\text { Crude } \\
\text { OR }(95 \% C I)^{*}\end{array}$ \\
\hline Managerial and professional & 87 & 101 & 0.87 (0.61 to 1.22$)$ & 74 & 81 & $1.02(0.73$ to 1.45$)$ \\
\hline Nurse & 13 & 18 & $0.76(0.36$ to 1.57$)$ & 13 & 14 & $1.03(0.47$ to 2.22$)$ \\
\hline Teacher & 39 & 43 & 0.96 (0.60 to 1.53$)$ & 30 & 25 & $1.36(0.78$ to 2.35$)$ \\
\hline Librarian & 2 & 3 & $0.71(0.11$ to 4.26$)$ & 1 & 0 & - \\
\hline Computer scientist & 3 & 1 & $3.20(0.33$ to 31.03$)$ & 0 & 0 & - \\
\hline Managers and administrators & 13 & 19 & $0.71(0.35$ to 1.47$)$ & 24 & 22 & $1.22(0.67$ to 2.22$)$ \\
\hline Technician, sales and administrative support & 132 & 144 & 0.93 (0.65 to 1.28$)$ & 199 & 236 & $0.90(0.69$ to 1.17$)$ \\
\hline Precision, production, craft, and repair & 8 & 2 & $4.29(0.90$ to 20.35$)$ & 10 & 11 & $1.02(0.43$ to 2.43$)$ \\
\hline Service occupations & 39 & 38 & $1.09(0.68$ to 1.76$)$ & 74 & 66 & 1.31 (0.91 to 1.88$)$ \\
\hline Machine operators, fabricators, and labourers & 21 & 22 & $1.00(0.54$ to 1.86$)$ & 60 & 68 & 0.99 (0.67 to 1.44$)$ \\
\hline Farming and forestry & 3 & 1 & $3.17(0.33$ to 30.66$)$ & 2 & 3 & $0.75(0.12$ to 4.49$)$ \\
\hline
\end{tabular}

^Mantel-Haenszel method was used to estimate ORs and $95 \%$ CIs.

The reference group consists of all women whose occupation of longest duration was not in the category under investigation. This includes 43 women who were never employed. Two postmenopausal cases and four postmenopausal controls were excluded because of missing data.

0.61 to 1.22 ). There were no increases in risk detected for specific occupational titles within this category, nurse, teacher, librarian, managers, and administrators. Premenopausal women whose occupation of longest duration was computer scientist had a threefold nonsignificant increase in risk compared with the controls (95\% CI 0.33 to 31.03 ).

An increased risk of breast cancer was found for premenopausal women who reported an occupation in the category of precision production, craft, and repair as their main lifetime job. However, the $95 \%$ CI was wide, reflecting the small number of cases, and included unity (OR $4.29,95 \%$ CI 0.90 to 20.35 ).

No association between postmenopausal breast cancer and major job was found in either of the occupational categories of precision production, craft, and repair, or managerial and professional specialties. However, two occupational groups within the managerial and professional specialty category were associated with a small non-significant increase in risk of postmenopausal breast cancer, teachers (OR $1.36,95 \%$ CI 0.78 to 2.35 ), and managers and administrators (OR 1.22, 95\% CI 0.67 to 2.22). Women whose main job was a service occupation had a small non-significant increase in the risk of postmenopausal breast cancer.

We found an inverse relation between breast cancer and having ever been employed in a job in a service occupation (OR $0.53,95 \%$ CI 0.34 to 0.82 ) (table 3 ). In examination of duration of employment in all jobs in this category, premenopausal women who worked one to 10 years in such occupations experienced the greatest reduction in risk (OR $0.47,95 \%$ CI
0.29 to 0.77 ), a smaller decrease in risk was found for women who worked 11 years or more.

No relation was found between having ever been employed in a managerial or professional occupation and postmenopausal breast cancer. After adjustment for confounders, there was a slight non-significant increase in risk for women who worked 11 years or more in a managerial or professional occupation (OR $1.10,95 \%$ CI 0.68 to 1.76 ). Results did not change after adjusting for duration of lactation or fruit and vegetable consumption.

\section{Discussion}

This is one of the first studies of breast cancer to consider lifetime occupational history. Conducting interviews with cases and controls allowed us to obtain complete and detailed information about all jobs which participants held and about other risk factors for breast cancer, enabling us to examine risk related to employment in selected occupations and to study risk associated with duration of employment while controlling for important potential confounders. Also, ours is one of few occupational studies of incident cases of breast cancer to use analytical epidemiology rather than rely on mortality data with the inherent limits in occupational data.

Several limitations of this study must be considered. The response rates for both cases and controls were low, which may have compromised the generalisability of the study. Nonparticipation among cases was primarily related to refusal of the physician to allow us to contact patients. These refusals may have been related

Table 3 Premenopausal and postmenopausal breast cancer risk associated with employment in the managerial and professional specialty occupational category

\begin{tabular}{|c|c|c|c|c|c|c|c|c|}
\hline & \multicolumn{4}{|c|}{ Premenopausal } & \multicolumn{4}{|c|}{ Postmenopausal } \\
\hline & Cases & Controls & $\begin{array}{l}\text { Crude } \\
\text { OR }\end{array}$ & $\begin{array}{l}\text { Adjusted } \dagger \\
O R^{\star}(95 \% C I)\end{array}$ & Cases & Controls & $\begin{array}{l}\text { Crude } \\
\text { OR* }\end{array}$ & $\begin{array}{l}\text { Adjusted } \dagger \\
O R^{\star}(95 \% C I)\end{array}$ \\
\hline Never & 194 & 166 & 1.00 & 1.00 & 329 & 377 & 1.00 & 1.00 \\
\hline Ever & 107 & 149 & 0.61 & $0.53(0.34$ to 0.82$)$ & 108 & 116 & 1.07 & $1.03(0.72$ to 1.50$)$ \\
\hline $1-10 y$ & 44 & 73 & 0.52 & $0.47(0.29$ to 0.77$)$ & 41 & 43 & 1.09 & $1.02(0.61$ to 1.69$)$ \\
\hline$\geqslant 11 \mathrm{y}$ & 62 & 74 & 0.72 & $0.64(0.37$ to 1.10$)$ & 66 & 69 & 1.10 & $1.10(0.68$ to 1.76$)$ \\
\hline
\end{tabular}

${ }^{\star}$ Odds ratios were computed using logistic regression.

†Odds ratios were adjusted for age, education, age at menarche, age at first birth, family history of breast cancer, history of benign breast disease, and Quetelet index. Odds ratios were adjusted for age at menopause in the analyses of postmenopausal breast cancer. 
to patients' stage of disease, with physicians possibly refusing to permit us to contact patients with more advanced disease. If this were true, these results would not generalise to that group. Furthermore, if cases at more advanced stages were less likely to be included in this study, and if occupation were related to stage of disease results may be biased. For example, if perhaps due to better access to healthcare, women in professional and managerial occupations were more likely to have regular mammograms and so be diagnosed with breast cancer at earlier stages than blue collar workers, professionals and managers may have been overrepresented in our case group. In this instance, the ORs reported here are overestimated. Bias could also have resulted if occupation were related to nonparticipation among controls.

It could be speculated that professional women are more health conscious and therefore more likely to participate as controls. This bias might explain our finding of an inverse relation between employment in these occupations and risk of breast cancer. However, we conducted a study of non-participants which included questions on diet and cigarette smoking. ${ }^{34}$ Although we have no occupational information on non-participants, the results from this study seem to indicate that participants were not more health conscious than non-participants. These findings do not support the theory that, if professional women were more health conscious they would be more likely to participate as controls. Nevertheless, eligible controls who had been employed in a managerial or professional specialty still may have been more likely to participate than other women. If they were less likely to participate, the true risks are even lower than those found.

Women have often been excluded from occupational studies because of small samples. ${ }^{40}$ When we included the entire occupational histories, our results indicated that most women have held at least one job outside the home indicating that occupational exposures can not be ignored for women. We also found that most women hold more than three different jobs throughout their life. In studying occupational risk factors in women, this characteristic has created difficulties with study designs such as industry based cohorts or casecontrol studies, which use only the most recent or usual job.

Our analyses of job of longest duration suggested that employment in occupational categories of precision production, craft, and repair may increase the risk of premenopausal breast cancer and that women employed in service occupations may be at increased risk of postmenopausal breast cancer. These occupational categories are broad in scope, and included several occupations and exposures. Also, analyses for job of longest duration were based on a few subjects and therefore must be interpreted with caution. The small sample sizes also limited the power to detect small increases in risk.

No increase in risk of breast cancer was found among premenopausal or postmeno- pausal women whose job of longest duration was in the occupational category managerial and professional specialties. Apart from computer scientists, individual occupations among premenopausal women did not seem to be associated with risk of breast cancer in the analyses of job of longest duration. Results of analyses for the titles librarian and computer scientist were based on few study participants and must be interpreted with caution. A small increase in risk was indicated for postmenopausal women with a job of longest duration in the teaching or managerial and administration profession.

When lifetime occupational history was considered, a decreased risk of breast cancer was found among premenopausal women who had ever worked in a professional or managerial job. This association was stronger for women who were employed in a professional or managerial occupation for less than 10 years compared with long term workers (greater than 10 years). Thus, it seems that duration of employment in this occupational group is not related to risk.

Apart from a non-significant increase in risk experienced by a subset of women who worked for one to 10 years in an occupation in the managerial and professional specialties category, there was no relation between employment in these occupations and breast cancer among postmenopausal women.

These results contrast with several previous studies which indicated that women for whom the usual $^{910131517}$ or current ${ }^{11}$ occupation was a professional or managerial specialty were at increased risk of breast cancer. Our study differed from earlier studies in that we examined premenopausal and postmenopausal breast cancer separately, included all jobs held throughout participants' lifetimes, and adjusted for other risk factors for breast cancer. Risk estimates did not change much with adjustment in the present study. Nevertheless, the detected positive relation between professional employment and breast cancer in other studies may be explained by the later age at first birth among these women. The relation found previously may also be explained in part by other biases related to occupations as reported on women's death certificates - for example, the propensity for homemaker and professional titles to be overreported. Inaccuracies in the recording of the usual occupation on death certificates could introduce significant bias to results of studies that use these data. When comparing occupational data from death certificates to occupational histories, Schade et al found poor match rates over all for usual occupations. ${ }^{41}$ Among women, the match rates for individual usual occupations were all under $60 \%$. Secondly, there may be a considerable difference between assessing risk associated with having a history of work in a particular occupation and assessing risk related to usual occupation. These different methods could lead to different results if participants had been employed in several occupations throughout their lives, as we found among most of our participants. 
Women in upper white collar and high ranking occupational positions did not have an increased risk of breast cancer in a previously conducted cohort study. ${ }^{42}$ Also, in two population based case-control studies, ${ }^{43}{ }^{44}$ increases in risk of breast cancer among professionals and managers were not apparent. In the first study, ${ }^{42}$ the investigators examined risk relative to the three main jobs participants reported, and found no significant increases in risk of breast cancer associated with any of the professional occupational titles examined including nurse, teacher, mathematical and computer scientist, and writer. More recently, Coogan et $a l^{44}$ conducted a case-control study examining risk associated with usual occupation. There was no increase in risk of breast cancer associated with employment in either occupational category, executive, administrative and managerial, or professional specialties. Analyses of specific occupational titles showed a nonsignificant deficit of risk among nurses, no increase in risk among teachers, and a non-significant increase in risk for librarians.

Results of studies which did not indicate an increased risk of breast cancer associated with professional employment seem to also contrast with results of studies which showed positive relations with high socioeconomic status and risk of breast cancer. ${ }^{24-7}$ However, in these studies, investigators measured socioeconomic status at the time of diagnosis based on variables such as family income and did not consider the women's occupations. Perhaps socioeconomic status based on these variables at the time of diagnosis is related to other non-occupational risk factors for breast cancer.

In our study, women who never worked in professional or managerial occupations may have been more likely to have held jobs involving exposure to substances which put them at higher risk of breast cancer compared with professional women. For example, a greater percentage of premenopausal women who never worked in a professional or managerial occupation reported having worked in at least one job in the precision production, craft, and repair category, a category which was associated with an increased risk of premenopausal breast cancer.

Additional studies with occupational histories are necessary to confirm our findings. Larger studies which identify specific exposures involved in precision production, craft, and repair occupations are necessary. Analyses are currently under way linking occupational histories to job exposure matrices to further investigate risk of breast cancer relative to occupational exposures.

This research was supported in part by grant CA11535 and CA09051 from the National Cancer Institute. JLF is the recipient of a PHS research cancer development award (CA-01633) from the National Cancer Institute. This research is the sole responsibility of the authors and does not necessarily represent the views of the National Cancer Institute.

1 Hoel DG, Davis DL, Miller AB, et al. Trends in cancer mortality in 15 industrialized countries, 1969-86. I Natl Cancer Inst 1992;84:313-20.
2 Kelsey, JL, Gammon MD. Epidemiology of breast cancer. Epidemiol Rev 1990;12:228-40.

3 Glass AG, Hoover RN. Rising incidence of breast cancer: relationship to stage and receptor status. $\mathcal{F}$ Natl Cancer Inst 1990;82:693-6.

4 Graham S, Levin M, Lilienfeld AM. The socioeconomic distribution of cancer of various sites in Buffalo, NY, 194852. Cancer 1960;13:180-91.

5 Carter CL, Jones DY, Schatzkin A, et al. A prospective study of familial, reproductive, and socioeconomic risk factors for breast cancer using NHANES I data. Public Health Reports 1989;104:45-50.

6 Poletto L, Morini JC. Cancer mortality and some socioeconomic correlates in Rosario, Argentina. Cancer Lett 1990;49:201-5.

7 Ewertz M. Risk of breast cancer in relation to social factors in Denmark. Acta Oncol 1988;27:787-92.

8 Goldberg MS, Labrèche F. Occupational risk factors for female breast cancer: a review. Occup Environ Med female breast canc

9 Rubin CH, Burnett CA, Halperin WE, et al. Occupation as a risk identifier for breast cancer. Am F Public Health 1993; 83:1311-5.

10 Bulbulyan M, Zahm SH, Zaridze DG. Occupational cancer mortality among urban women in the former USSR. Cancer Causes Control 1992;3:299-307.

11 Kato I, Tominaga S, Ikari A. An epidemiological study on occupation and cancer risk. $\mathcal{F p n} \mathcal{F}$ Clin Oncol 1990;20:1217.

12 Cantor KP, Brinton LA, Stewart P, et al. Associations of occupation and industry from death certificates with breast cancer mortality in a case-control analysis. International Conference on Women's Health: Occupation and Cancer; 1993 Nov 1-2. Baltimore, MD: 1993.

13 Morton WE. Major differences in breast cancer risks among occupations. F Occup Environ Med 1995;37:328-35.

14 Gunnersdottir H, Rafnsson V. Cancer incidence among Icelandic nurses. F Occup Environ Med 1995;37:307-12.

15 King AS, Threfall WJ, Band PR, et al. Mortality among female registered nurses and school teachers in British Columbia. Am f Ind Med 1994;26:125-32.

16 Doebbert G, Riedmiller KR, Kizer KW. Occupational mortality of California women, 1979-81. West $\mathcal{F}$ Med 1988; 149:734-40.

17 Roman E, Beral V, Inskip H. Occupational mortality among women in England and Wales. BMF 1985;291:194-6.

18 Lynge E, Thygesen L. Occupational cancer in Denmark. Cancer incidence in the 1970 census population. Scand $\mathcal{F}$ Work Environ Health 1990:16(suppl 2):3-35.

19 Spirtas R, Stewart PA, Lee JS, et al. Retrospective cohort mortality study of workers at an aircraft maintenance facility. I epidemiological results. Br F Ind Med 1991;48:515ity. I

20 Cantor KP, Stewart PA, Brinton LA, et al. Occupational exposures and female breast cancer mortality in the United exposures and female breast cancer mortality in
States. F Occup Environ Med 1995;37:336-48.

21 Shannon HS, Haines T, Bernholz C, et al. Cancer morbidity in lamp manufacturing workers. Am F Ind Med 1988;14 281-90.

22 Pukkala E, Nokso-Koivisto P, Roponen P. Changing cancer risk pattern among Finnish hairdressers. Int Arch Occup Environ Health 1992;64:39-42.

23 Gubéran E, Raymond L, Sweetnam PM. Increased risk for male bladder cancer among a cohort of male and female hairdressers from Geneva. Int F Epidemiol 1985;14:54954.

24 Teta MJ, Walrath J, Meigs JW, et al. Cancer among cosmetologists. F Natl Cancer Inst 1984;72:1051-5.

25 Kono S, Tokudome S, Ikeda M, et al. Cancer and other causes of death among female beauticians. 7 Natl Cancer causes of death amo
Inst 1983;70:443-6.

26 Loomis DP, Savitz DA, Ananth CV. Breast cancer mortality among female electrical workers in the United States. $\mathcal{F}$ Natl Cancer Inst 1994;86:921-5.

27 Dosemeci M, Blair A, Occupational cancer mortality among women employed in the telephone industry. F Occup Environ Med 1994;36:1204-9.

28 Adams EE, Brues AM. Breast cancer in female radium dial workers first employed before 1930. F Occup Med 1980; 22:583-7

29 Stebbings JH, Lucas HF, Stehney, AF. Mortality from cancers of major sites in female radium dial workers. Am f Ind Med 1984;5:435-59.

30 Baverstock KF, Vennart J. A note on radium body content and breast cancer in UK radium illuminators. Health Phys 1983;44:575-7.

31 Wang J, Inskip PD, Boice JD, et al. Cancer incidence among medical diagnostic $x$ ray workers in China, 1950-85. Int $\mathfrak{f}$

32 Boice JD Jr, Mandel JS, Doody MM. Breast cancer among radiologic technologists. $\mathcal{F A M A} 1$ 1995;274:394-401.

33 Doody MM, Morin JS, Boice JD Jr. Employment practices and breast cancer among radiologic technologists. F Occup Enivron Med 1995;37:321-7.

34 Graham S, Hellman R, Marshall J, et al. Nutritional epidemiology of postmenopausal breast cancer in western New York. Am $\mathcal{F}$ Epidemiol 1991;137:552-6.

35 Freudenheim JL, Marshall JR, Vena JE, et al. Premenopausal breast cancer risk and intake of vegetables, fruits, and related nutrients. F Natl Cancer Inst 1996;88:340-8.

36 US Department of Commerce. 1980 Census of the population, alphabetical index of industries and occupations. Washington, DC, US Government Printing Office, 1980. (Publication number 80-R3.) 
37 Mantel N, Haenszel W. Statistical aspects of the analysis of data from retrospective studies of disease. $\mathcal{F} \mathrm{Natl}$ Cancer Inst 1959;22:719-48.

38 Breslow NE, Day NE. Statistical methods in cancer research Vol 1 The analysis of case-control studies. Lyon: Internationa Agency for Cancer Research, 1980. (IARC Publication number 32.)

39 SPSS. SPSS Version 4 reference guide. Chicago, Il: SPSS, 1990

40 Hoar Zahm S, Pottern LM, et al. Inclusion of women and minorities in occupational cancer epidemiologic research. $\mathcal{f}$ Occup Environ Med 1994;36:842-7.

41 Schade WJ, Swanson M. Comparison of death certificate occupational and industry data with lifetime occupational histories obtained by interview: variations in death
certificate entries. Am ₹ Ind Med 1988;14:121-36.

42 Van Loon AJ, Goldbohm RA, Van Den Brant PA. Socioeconomic status and breast cancer incidence: a prospective cohort study. Int $\mathcal{F}$ Epidemiol 1994;23:899-905. 43 Habel LA, Stanford JL, Vaughan TL, et al. Occupation and breast cancer risk in middle-aged women. F Occup Environ Med 1995;37:349-56.

44 Coogan PF, Clapp RW, Newcomb PA, et al. Variation in female breast cancer risk by occupation. Am $\mathcal{F}$ Ind Med 1996;30:430-7.

\section{Occupational and Environmental Medicine - http://www.occenvmed.com}

Visitors to the world wide web can now access Occupational and Environmental Medicine either through the BMJ Publishing Group's home page (http://www.bmjpg.com) or directly by using its individual URL (http://www.occenvmed.com). There they will find the following:

- Current contents list for the journal

- Contents lists of previous issues

- Members of the editorial board

- Subscribers' information

- Instructions for authors

- Details of reprint services.

A hotlink gives access to:

- BMJ Publishing Group home page

- British Medical Association website

- Online books catalogue

- BMJ Publishing Group books.

The web site is at a preliminary stage and there are plans to develop it into a more sophisticated site. Suggestions from visitors about features they would like to see are welcomed. They can be left via the opening page of the BMJ Publishing Group site or, alternatively, via the journal page, through "about this site". 